\title{
A Review on Online Pharmacy
}

\author{
G.Prashanti, S.Sravani, Saleha Noorie \\ Dept of pharmaceutical technology, AU College of Pharmaceutical sciences, Visakhapatnam, A.P.
}

\begin{abstract}
In recent years there is a tremendous increase in online shopping for different commodities like cloth, jewellery and the sale of medicines have been increased via onlinel internet. Online pharmacy is one of the technology advancements that is about to create a huge demand in the upcoming days. Though it is convenient to get them, there is high risk of self medication and misuse of drugs especially that come under schedule $H$ and $X$. In this article we have discussed in detail about online pharmacy, its advantages and disadvantages, differences between online and local pharmacy, and certain measures to avoid misuse of e-pharmacy.
\end{abstract}

Keywords: Self medication, online pharmacies, laws of pharmacy, prescription

\section{Introduction}

In past, the best communication method for physicians in decisions relating to medication for pharmacists to distribute medicines was hand written prescription. Now it is being replaced by electronic prescription network commonly known as e-pharmacy/online pharmacy.

Online pharmacies are companies that sell pharmaceutical preparations that include prescription-only drugs, on the Internet via online ordering and mail delivery. Online pharmacies can be classified basically as:

(1) Legitimate Internet pharmacy websites providing high-quality pharmacy services according to verification standards, and

(2) Illegitimate online pharmacies that are not verified and may not comply with national or international professional standards and regulations.

Advantages:

Online pharmacy market has undoubted advantages for patients:

- Access to drugs for the disabled or housebound,

- Access 24 hours a day,

- A virtually unlimited number of products available,

- Relative privacy, which may encourage patients to ask questions about embarrassing issues, and more affordable prices.

- Free access to information, comparison shopping.

Disadvantages:

- Lack of meaningful interaction with physician and pharmacists.

- In many cases, customers are not aware that products offered by online pharmacies may not have the same quality that a retail pharmacy may offer.

- It is difficult to determine whether a website is legitimate or not, because it is difficult to determine whether drugs purchased online are counterfeit, unapproved, or illegal.

- Misdiagnosis and inappropriate use of medicines. These disadvantages and dangers are further exacerbated in the case of unlicensed and illegally operated online pharmacies.

\section{Some other issues associated with the online availability of medicines:}

- This encourages more self-medication.

- The medicines do require appropriate storage for retaining potency. There is no assurance of temperature control either at their storage points or during transport.

- The patients loose the opportunity to have a face to face discussion with the professional pharmacists.

- The brand names may often cause confusion. There may be the same brand but with different drugs. Ultimately, the patient is at receiving and getting wrong medicines.

- The most worried thing is the sale of antibiotics; India is already fighting against antibiotic resistance for irrational use of antibiotics. 


\section{Laws Of Pharmacy}

According to Supreme Court statement, except in emergency cases, doctor cannot consult through phone. As far as India is concerned, there are no dedicated e-health and telemedicine laws in India.

There are no well-defined dedicated laws for online pharmacies. The laws applicable are:

- Drug and Cosmetics Act 1940,

- Drugs and Cosmetic Rules 1945,

- Pharmacy Act 1948,

- Indian Medical Act 1956 and

- Laws related to e-commerce are defined under the Information Technology Act, 2000.

\section{Role Of Prescription}

- Online pharmacies will promote drug abuse, drug misuse, self-medication, etc. Self-medication is a rampant practice in India, and online sale of drugs would only encourage it.

- Any medication taken without the supervision of doctors may be dangerous and even potentially lifethreatening.

- A prescription issued by a doctor cannot be re-used randomly. There is a danger that scheduled drugs can be re-ordered and misused by the consumer.

- The D\&C Act 1940, and the D\&C Rules 1945 has guidelines on the sale of Schedule H and Schedule X drugs. These can be sold only on prescription, and there are specific rules, including for labeling and bar coding.

- Schedule X drugs include narcotics and psychotropic substances. Chances of drug abuse and addiction are higher with the Schedule X category. Schedule X drugs require meticulous storage and dispensing records. The prescription has to be in duplicate and one copy of which is to be retained by the licensed pharmacist for 2 years.

\section{Comparison Of Local Pharmacy And Online Pharmacy}

- Price: The prices for medications from an online pharmacy are less because there is no particular production unit and there is no physical store for the medications storage and dispensing and the company has a large network of retailers to draw from, or a combination of factors.

- Convenience: Prescription can be submitted at any time, there is no need to rush to the pharmacy during business hours and don't have to wait in any long lines. However, there are also disadvantages. If it is not the same website every time, one may not be aware of any potential drug interactions, it can be difficult to find someone to answer any specific questions about medications.

- Local pharmacies are small independently owned business rather than a pharmacy within one of the large chains and they have staff during regular business hours, and many also have an online counterpart as well. The large chains do use locals for a large portion of their workforce.

- Pharmacist is responsible for dispensing the right medicines and even counseling a patient about sideeffects and dosage. In the online space, where the medicines are delivered at the patient's home, there is no possibility of an interaction between a patient and a pharmacist.

\section{Measures To Be Taken To Avoid The Misuse Of Online Pharmacy}

- Before preventing the misuse of online pharmacy, patients should stop the nonmedical use of prescription drugs like stimulants, sedatives or opiod pain relievers. Patients can take steps to ensure that they use prescription medications appropriately by:

- never change a dosing regimen without first discussing it with the doctor

- never using another person's prescription, and never giving their prescription medications to others

- storing prescription stimulants, sedatives, and opioids safely

- patients should properly discard unused or expired medications

- Schedule $\mathrm{H}$ and schedule $\mathrm{X}$ drugs cannot be sold without prescription because it is easy for local pharmacy stores to verify the authencity of a prescription, as it contains details like registration number of medical practitioner and name of the hospital and there is no such checking by online stores.

- According to the report of high level government committee since doctor's prescription is mandatory for purchasing drugs, online pharmacies will need to mandatorily display the portal link on their homepage for authencity verification by patients or customers and the prescriptions should be digitally signed by the physicians.

- In certain countries like United States, England, Sweden, Denmark and Finland have accurate, regular, and systematic plans to use electronic prescription system, and health ministry of these countries was 
responsible for coordinating and leading the electronic health. It is suggested to use experiences and programs of the leading countries to design and develop the electronic prescription systems.

\section{Conclusion}

Though e-pharmacy is more liable than local pharmacy especially in remote areas, it should be aimed to establish rules and regulation like upload of scanned prescriptions. Patients should be aware on use of prescription medications. It would be good to adopt the plans and programmes of leading countries to design and develop the e-pharmacy system.

\section{References}

[1] A Comparative Review of Electronic Prescription Systems: Lessons Learned from Developed Countries Mahnaz Samadbeik, Maryam Ahmadi, Farahnaz Sadoughi, Ali Garavand, Journal of Research in Pharmacy Practice i Volume 6 ; Issue 1 i JanuaryMarch 2017.

[2] Quality of Online Pharmacies and Websites Selling Prescription Drugs: A Systematic Review Grazia Orizio, MD, PhD, Anna Merla, MD, Peter J Schulz, PhD, and Umberto Gelatti, MD . Journal of Medical Internet Research

[3] National institute of Drug Abuse, Misuse of Prescription Drugs.

[4] Online pharmacy, Wikipedia, free encyclopaedia.

[5] Regulating Online Pharmacies: The Challenges Ahead. 